\title{
An isolated orbital mass with proptosis and diplopia: an uncommon metastasis from intracranial olfactory neuroblastoma in a Chinese patient
}

This article was published in the following Dove Press journal:

OncoTargets and Therapy

24 August 2016

Number of times this article has been viewed

\author{
Jianqin Shen' \\ Hongguang Cui' \\ Shi Feng ${ }^{2}$
}

'Department of Ophthalmology, ${ }^{2}$ Department of Pathology, The First Affiliated Hospital, School of Medicine, Zhejiang University, Hangzhou, People's Republic of China
Correspondence: Hongguang Cui Department of Ophthalmology, The First Affiliated Hospital, School of Medicine, Zhejiang University, 79 Qingchun Road, Hangzhou 310003, People's Republic of China

Tel $+8657 \mid 87236790$

Fax +8657187236393

Email chgzyyk@126.com
Purpose: Olfactory neuroblastoma (ONB) is a rare neuroectodermal malignant neoplasm that originates from the olfactory sensory epithelium. In reported cases involving the orbit, the primary neoplasms could invade the orbits through bone destruction or cranio-orbital communication anatomical structure. The present study reports a rare case of orbital metastatic tumor arising from an intracranial ONB in a Chinese patient, which is the first case demonstrating an uncommon route of ONB involving the orbit.

Patient and methods: A 62-year-old man with a right orbital tumor was diagnosed as having a secondary tumor arising from intracranial ONB. Clinical examination, including ocular imaging examination, and histopathological and immunohistochemical studies were performed.

Results: In the ocular examination, a focal, firm, nontender swelling with ill-defined margins in the right orbit was found on palpation. Proptosis, limited eyeball movement, and visual loss were also observed. The unenhanced computed tomography scan showed a homogeneous, isolated, ill-defined soft tissue neoplasm in the right orbit. The histopathological study revealed irregularly shaped nests of tumor cells surrounded by avascularized fibrous stroma. The monomorphic malignant tumor cells are small round blue cells that are slightly larger than mature lymphocytes, with a very high nuclear to cytoplasmic ratio. The immunohistochemical staining for tumor cells was positive for synaptophysin, chromogranin A, cluster of differentiation 56 (CD56), cytokeratin, vimentin, S-100 protein, and negative for epithelial membrane antigen, and cluster of differentiation (CD99).

Conclusion: This is so far the first Chinese case of orbital metastasis from intracranial ONB that has ever been reported. Metastasis might be another route of ONB invading the orbit besides direct invasion.

Keywords: olfactory neuroblastoma, orbit, metastasis, pathology, computed tomography

\section{Introduction}

First described by Berger in 1924, olfactory neuroblastoma (ONB) is a rare malignant neoplasm arising from the olfactory epithelium. ${ }^{1}$ The incidence of ONB is $\sim 0.4$ in a million per year. It can appear at any age but normally displays a bimodal distribution with two peaks, in the second and sixth decade of life, without a predilection for sex..$^{2,3}$ Cases of ONB with ophthalmologic presentations, including epiphora, decreased visual acuity, and proptosis, have been reported previously. ${ }^{4-9}$ In these orbital malignant cases, the infiltrating neoplasm invaded orbits directly through bone destruction or the cranio-orbital communication anatomical structure. Herein we report a novel case of orbital metastasis from intracranial ONB in a Chinese patient demonstrating a possible uncommon approach of ONB migration to orbits. 


\section{Patient and methods}

\section{Clinical data}

The patient's clinical data were reviewed, including findings from the ocular examination and computed tomography (CT) scan. The study was approved by the Human Subjects Ethics Subcommittee of Zhejiang University, and it adhered to the tenets of the Declaration of Helsinki. Written informed consent was obtained from the patient.

\section{Histopathology and immunohistochemistry}

Surgical samples were collected and embedded with paraffin for histological and immunohistochemical analyses. Immunohistochemical analyses for synaptophysin (SYN) (rabbit monoclonal antibody, OriGene, Rockville, MD, USA), chromogranin A (CGA; mouse monoclonal antibody; OriGene), cluster of differentiation (CD56; mouse monoclonal antibody; OriGene), cytokeratin (CK; mouse monoclonal antibody; OriGene), vimentin (VIM; mouse monoclonal antibody; OriGene), S-100 protein (mouse monoclonal antibody, OriGene), epithelial membrane antigen (EMA; mouse monoclonal antibody; OriGene), and cluster of differentiation 99 (CD99; mouse monoclonal antibody; OriGene) were performed on the paraffin sections.

\section{Results}

\section{Case report}

A 62-year-old male was referred to our department complaining of proptosis and diplopia in his right eye for the past 2 months. He also noticed a rapidly increasing swelling in the superior position of the right orbit 1 month ago. He had surgery twice previously: the first for a bladder carcinoma 12 years ago, and the second for an intracranial ONB in the frontal lobe and saddle area 6 months ago. Adjuvant postoperative radiation therapy was given after the craniotomy. His father died of esophageal carcinoma.

The ocular examination revealed proptosis and mild infratemporal deviation with limited eyeball movement. The fundus examination showed mild retinal edema and venous congestion. The visual acuity of the right eye was decreased to 5/12 with normal intraocular pressure. A focal, firm, nontender swelling with ill-defined margins was found through palpation in the upper position of the right eye. Lymph node enlargement was not detected on palpation. An unenhanced CT scan of the orbit was performed in the axial section with coronal and sagittal reconstructions. CT showed a homogeneous, isolated, ill-defined soft tissue mass in the right orbit. The right eyeball was displaced anteriorly and inferiorly (Figure 1). Enhanced imaging examination was not performed due to renal dysfunction.

Extirpation of the lesion by anterior orbitotomy was performed under general anesthesia. A $4.0 \mathrm{~cm}$ incision through the skin along the supraorbital margin enabled adequate exposure of the neoplasm. The neoplasm was carefully detached from the normal tissues by blunt dissection. The mass measured $\sim 2.5 \times 2.5 \times 2.0 \mathrm{~cm}$.

Histopathological examination suggested that it was a highly cellular, infiltrative tumor. Tumor cells were seen in irregular shaped nests surrounded by avascularized fibrous stroma (Figure 2). The monomorphic malignant tumor cells are small round blue cells that are slightly larger than mature lymphocytes, with a very high nuclear to cytoplasmic ratio. Immunohistochemistry study was positive for SYN, CGA, CD56, CK, VIM, S-100 protein staining and negative for EMA and CD99 marker (Figure 3). Histological findings along with immunohistochemical staining results led to the diagnosis of orbital ONB which was consistent with primary tumor in the brain. The patient was advised to undergo radiotherapy and was referred to the department of radiation oncology.

\section{Discussion}

ONB is a rare malignant tumor that occurs in the neuroectodermal cells of the olfactory sensory epithelium. ${ }^{10}$ It shows no predilection for sex and occurs at any age (2-94 years), despite a bimodal age distribution in the second and sixth decades of life according to the previous reports. ${ }^{2,3}$ Due to the complex anatomical location and slow growth of the tumors, patients often have no symptom at the early onset, leading to a delay in diagnosis. However, when affecting adjacent structures (orbit and cranial cavity), the tumors may present as nontypical symptoms, including headaches, protopsis, strabismus, excessive lacrimation, rhinorrhea, and visual disturbances. The cell of origin in ONB is still controversial. Jacobson's vomeronasal organ, sphenopalatine ganglion, ectodermal olfactory placode, ganglion of Loci autonomic ganglia of the nasal mucosa, and the olfactory neuroepithelium were proposed to be the sites of origin for this neural crest-derived neoplasm. ${ }^{2,11}$

Radiography examination is helpful for differentiating the tumor from other tumors. Speckled calcifications and bone erosion can be picked up by CT with noncontrast enhanced methods, while contrast-enhanced CT highlights the areas of necrosis. Magnetic resonance imaging measures the extent of the tumor. T1-weighted images show hypointense-to-intermediate signals within the mass 

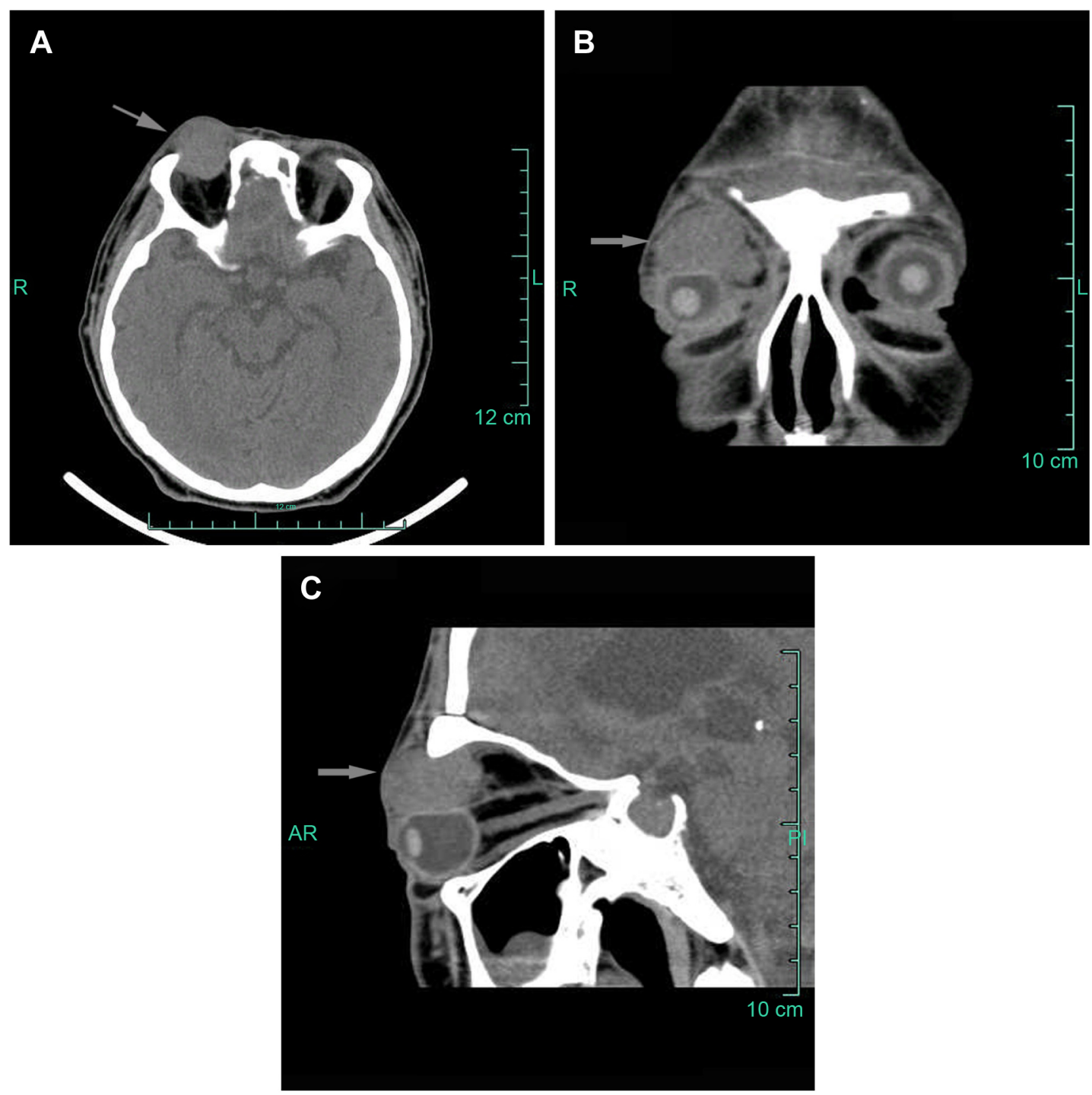

Figure I Computed tomography scans showing a homogeneous, isolated, ill-defined soft tissue density mass in the right orbit (A-C; arrows). The right eyeball was displaced anteriorly and inferiorly. (A) Axial section, (B) sagittal section, and (C) coronal section.

Abbreviations: $A R$, anterior; L, left; PI, posterior; $R$, right.

compared to normal brain tissue, and the hypointense signal tends to come from necrosis. T2-weighted images may show hyperintense regions, which correlate to the cystic regions at the advancing edge. There is often marked tumor enhancement after gadolinium. ${ }^{2}$ Sporadic cases of ONB with ophthalmologic presentations have been reported in the literature. ${ }^{4-9}$ In orbital tumor cases, the infiltrating neoplasm invades the orbit by bone destruction, which can be clearly observed by imaging examinations. ${ }^{12}$ However, in our patient's CT images, the orbital neoplasm was an isolated homogenous mass occupying the upper inner position of the right orbit, which does not support the possibility of direct invasion (Figure 1). The location and morphology of the orbital tumor in our case was unique compared to the ones mentioned in previous studies. ${ }^{4-9}$ Cytopathological and immunohistochemical features of the orbital neoplasm were found to be consistent with the features of primary intracranial tumors. So we speculate that the orbital neoplasm in our case is a metastasis rather than an infiltration from the primary lesion. Unfortunately, the enhanced imaging examination, which can otherwise further support our conclusion, was not performed for the patient's renal dysfunction. ONBs can metastasize to other organs through hematogenous and lymphatic routes. They have been previously found to metastasize to spinal cord, vertebral body, lung, and brain. ${ }^{13-16}$ However, to the best of our knowledge, there has been no case of ONB metastasizing to the orbit.

Compared to imaging approaches, the histopathological and immunohistochemical analyses were more reliable for diagnosing ONB. These histopathological characteristics in our 

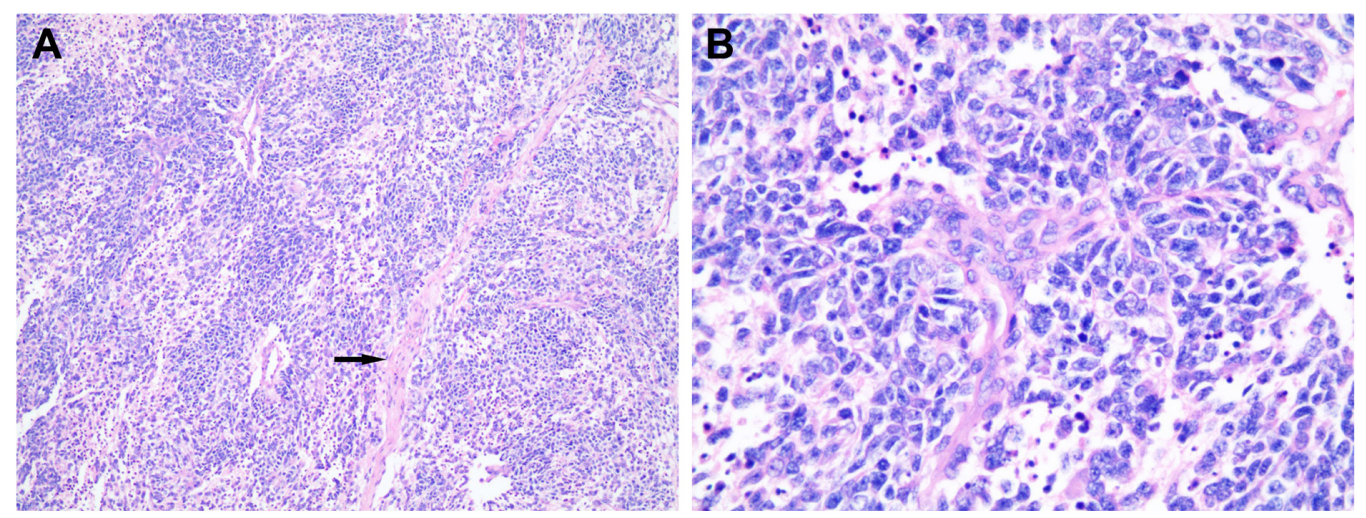

Figure 2 Histopathological sections of the mass.

Notes: (A) Irregularly shaped nests of tumor cells surrounded by avascularized fibrous stroma (arrow shows the avascularized fibrous stroma; hematoxylin and eosin staining; original magnification: $\times 100$ ). (B) The monomorphic malignant tumor cells are small round blue cells that are slightly larger than mature lymphocytes, with a very high nuclear to cytoplasmic ratio (hematoxylin and eosin staining; original magnification: $\times 400$ ).

case were similar to those reported in studies by Thompson, ${ }^{2}$ and Mahooti and Wakely. ${ }^{17}$ Due to its histological similarities to other malignant small round cell tumors, ONB has been confused histologically with other lesions, including sinonasal undifferentiated carcinoma, small-cell neuroendocrine carcinomas, Ewing's sarcoma, melanoma, and lymphoma. ${ }^{2,18-20} \mathrm{~A}$ broad panel of antibodies staining provides more information to distinguish ONB from other tumors (Table 1).,21-24 In our case, eight antigens were tested immunohistochemically, of which SYN, CGA, CD56, CK, VIM, and S-100 protein were positively stained, while EMA and CD99 were negatively stained. The majority of ONB cases express neuroendocrine markers, including SYN, CGA, CD56, and neuron-specific enolase. S-100 protein-positive peripheral dendritic cells corresponding to Schwann cells may present within the neoplasm or at the edges of tumor nests. EMA, CD99, desmin, myogenin, and CD45RB (leukocyte common antigen) negatively stain in ONBs and the staining of CK, VIM, glial fibrillary acidic protein, and neurofilaments in ONBs varies in the literatures..$^{25,26}$ Immunohistochemical staining of sinonasal undifferentiated carcinoma is positive for EMA and occasionally positive for SYN and CGA. S-100 is typically negative or rarely focally
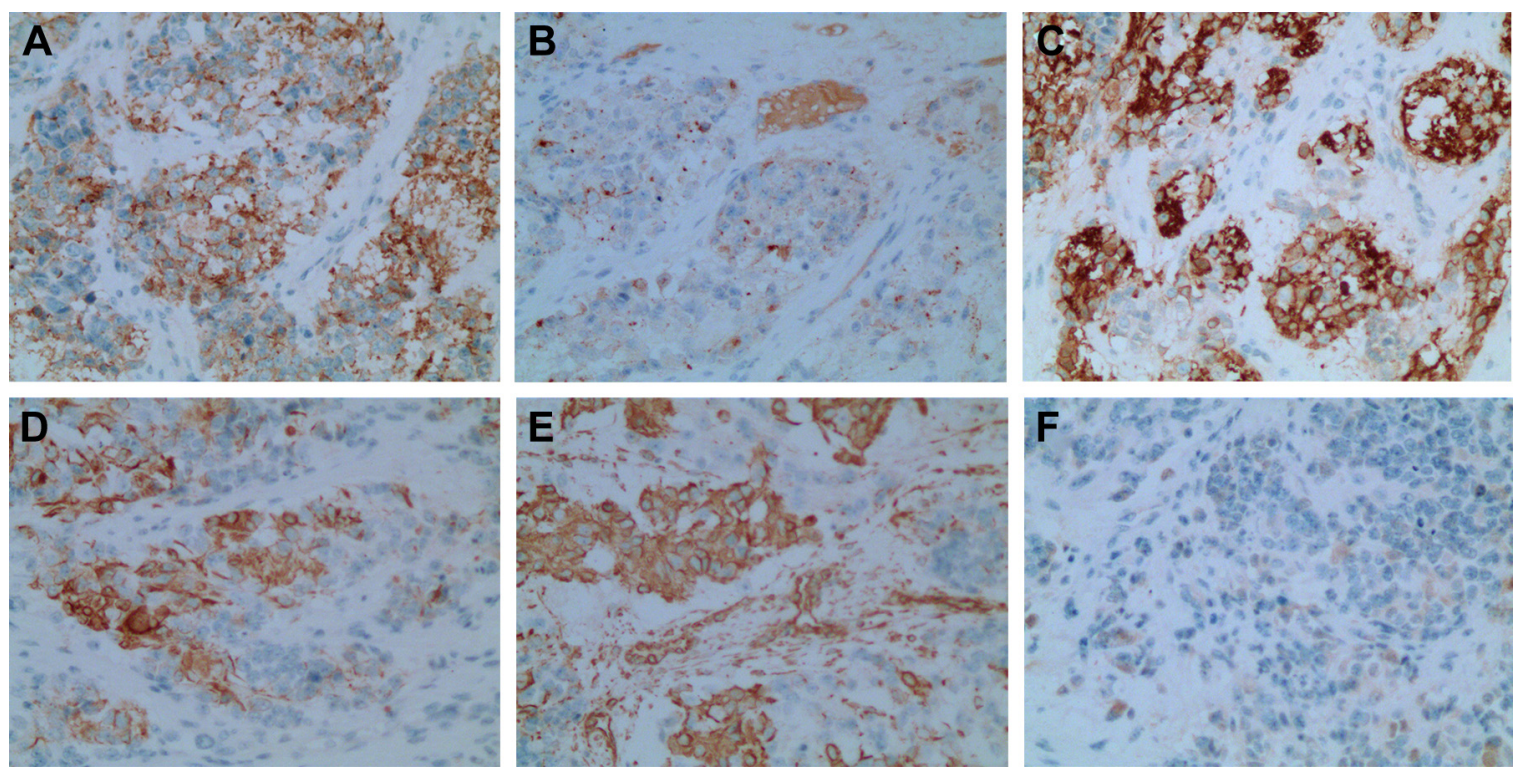

Figure 3 Immunohistochemical staining of the mass.

Notes: The tumor cells were positive for (A) SYN; original magnification: $\times 400$; a reaction in the cytoplasm of the neoplastic cells; (B) CGA; original magnification: $\times 400$; a reaction in the cytoplasm of the neoplastic cells; (C) CD56 (cluster of differentiation 56); original magnification: $\times 400$; a strong and heavy membrane-type staining; (D) CK; original magnification: $\times 400$; a reaction in the cytoplasm of the neoplastic cells; (E) VIM; original magnification: $\times 400$; a reaction in the cytoplasm of the neoplastic cells; (F) S- 100 protein; original magnification: $\times 400$; a sustentacular reaction. The tumor cells were negative for EMA and CD99 (data not shown),

Abbreviations: CD, cluster of differentiation; CGA, chromogranin; CK, cytokeratin; EMA, epithelial membrane antigen; SYN, synaptophysin; VIM, vimentin. 
Table I Selected immunohistochemical results for malignant small round cell tumors

\begin{tabular}{lllllll}
\hline mAB & ONB & SNUC & SCNC & EWS/PNET & MM & ML \\
\hline SYN & $+/-$ & $-l+$ & $-l+$ & $-l+$ & $\mathrm{R}+$ & - \\
CGA & $+/-$ & $-l+$ & $-l+$ & - & - & - \\
NSE & + & $+l-$ & $+l-$ & $+l-$ & $-l+$ & - \\
CK & $-/+$ & + & + & $\mathrm{R}+$ & $\mathrm{R}+$ & - \\
S-I00 & $+^{\mathrm{S}}$ & $\mathrm{R}+$ & $\mathrm{R}+$ & $-/+$ & + & - \\
EMA & - & $+l-$ & $\mathrm{n} / \mathrm{a}$ & $\mathrm{n} / \mathrm{a}$ & $\mathrm{R}+$ & - \\
HMB-45 & - & - & - & - & + & - \\
CD99 & - & $\mathrm{R}+$ & $\mathrm{R}+$ & + & $-/+$ & - \\
\hline
\end{tabular}

Abbreviations: SYN, synaptophysi; CGA, chromogranin A; NSE, neuron specific enolase; CK, cytokeratin; EMA, epithelial membrane antigen; HMB-45, human melanoma black 45; $C D$, cluster of differentiation; $m A B$, monoclonal antibodies; ONB, olfactory neuroblastoma; SNUC, sinonasal undifferentiated carcinoma; SCNC, small-cell neuroendocrine carcinoma; EWS/PNET, Ewing's sarcoma/peripheral neuroectodermal tumor; MM, malignant melanoma; ML, malignant lymphoma; +, positive; $+/-$, often positive, $-/+$, occasionally positive; $\mathrm{R}+$, rarely positive; $+^{\mathrm{s}}$, positive in peripheral sustentacular cells; -, negative; n/a, not applicable.

positive. Small-cell neuroendocrine carcinomas are typically negative for S-100 protein. As for Ewing sarcoma, melanoma, and lymphoma, neuroendocrine markers such as SYN, CGA combined with CK, S-100, EMA, HMB-45 (Human Melanoma Black 45), and CD99 are of great utility in eliminating other small cell malignancies, because these latter neoplasms (Ewing's sarcoma, melanoma, and lymphoma) are rarely positive for neuroendocrine markers..$^{1721-24}$

\section{Conclusion}

Unlike direct infiltration of ONB in previously reported orbital tumor cases, our present study represents an uncommon pathway of orbital involvement of tumor development from ONBs in a Chinese case. CT and magnetic resonance imaging were used to diagnose and determine the extent and staging of the tumor. It was unfortunate that the patient was unable to tolerate the contrast-enhanced imageological examination, which would have helped to understand the exact pathological mechanism of the metastasis. Histopathological and immunohistochemical analyses were used to confirm the primary ONB. Further studies are needed to clarify the mechanism of the rare orbital metastases route arising from ONBs.

\section{Disclosure}

The authors report no conflicts of interest in this work.

\section{References}

1. Kiyota N, Tahara M, Fujii S, et al. Nonplatinum-based chemotherapy with irinotecan plus docetaxel for advanced or metastatic olfactory neuroblastoma. Cancer. 2008;112(4):885-891.

2. Thompson LD. Olfactory neuroblastoma. Head Neck Pathol. 2009;3(3): $252-259$.
3. Morita A, Ebersold MJ, Olsen KD, Foote RL, Lewis JE, Quast LM. Esthesioneuroblastoma: prognosis and management. Neurosurgery. 1993; 32(5):706-715.

4. Ansari S, Ahmad K, Dhungel K, Gupta MK, Amanullah MF. Esthesioneuroblastoma: one of the causes of proptosis. Head Face Med. 2013;9:19.

5. Chan LP, Wang LF, Tai CF, Wu CC, Kuo WR. Huge sphenoid sinus olfactory neuroblastoma: a case report. Kaohsiung J Med Sci. 2009;25(2):87-92.

6. Kamath VB, Sowmya V, Ballal CK, Mendonca N. Esthesioneuroblastoma as an unusual cause for dystopia. Orbit. 2013;32(6):392-394.

7. Lopez R, Mazzoni L, Chaput B, Jalbert F. Olfactory neuroblastoma presenting with exclusive orbital manifestations. J Craniofac Surg. 2013;24(2):667-669.

8. Laforest C, Selva D, Crompton J, Leibovitch I. Orbital invasion by esthesioneuroblastoma. Ophthal Plast Reconstr Surg. 2005;21(6): $435-440$.

9. Bobele GB, Sexauer C, Barnes PA, Krous HF, Bodensteiner JB Esthesioneuroblastoma presenting as an orbital mass in a young child. Med Pediatr Oncol. 1994;22(4):269-273.

10. Dulguerov P, Allal AS, Calcaterra TC. Esthesioneuroblastoma: a metaanalysis and review. Lancet Oncol. 2001;2(11):683-690.

11. Broich G, Pagliari A, Ottaviani F. Esthesioneuroblastoma: a general review of the cases published since the discovery of the tumour in 1924. Anticancer Res. 1997;17(4A):2683-2706.

12. Yu T, Xu YK, Li L, et al. Esthesioneuroblastoma methods of intracranial extension: CT and MR imaging findings. Neuroradiology. 2009; 51(12):841-850.

13. Mori R, Sakai H, Kato M, et al. Olfactory neuroblastoma with spinal metastasis: case report. No Shinkei Geka. 2007;35(5):503-508.

14. Sasaki M, Sato M, Taguchi J, et al. A case of olfactory neuroblastoma with intracranial, intraorbital extension and multiple metastases. No Shinkei Geka. 1997;25(2):163-167.

15. Rodas RA, Erkman-Balis B, Cahill DW. Late intracranial metastasis from esthesioneuroblastoma: case report and review of the literature. Neurosurgery. 1986;19(4):622-627.

16. Jiang W, Liu J, Gullane PJ, et al. Non-contiguous meningeal metastases of olfactory neuroblastoma. J Neurooncol. 2016;126(1):201-203.

17. Mahooti S, Wakely PE Jr. Cytopathologic features of olfactory neuroblastoma. Cancer. 2006;108(2):86-92.

18. Sharma S, Sharma MC, Johnson MH, Lou M, Thakar A, Sarkar C. Esthesioneuroblastoma - a clinicopathologic study and role of DNA topoisomerase alpha. Pathol Oncol Res. 2007;13(2):123-129.

19. Meis-Kindblom JM, Stenman G, Kindblom LG. Differential diagnosis of small round cell tumors. Semin Diagn Pathol. 1996;13(3):213-241.

20. Mills SE, Fechner RE. "Undifferentiated" neoplasms of the sinonasal region: Differential diagnosis based on clinical, light microscopic, immunohistochemical, and ultrastructural features. Semin Diagn Pathol. 1989;6(4):316-328.

21. Bellizzi AM, Bourne TD, Mills SE, Stelow EB. The cytologic features of sinonasal undifferentiated carcinoma and olfactory neuroblastoma. Am J Clin Pathol. 2008;129(3):367-376.

22. D'cruze L, Dutta R, Rao S, R A, Varadarajan S, Kuruvilla S. The role of immunohistochemistry in the analysis of the spectrum of small round cell tumours at a tertiary care centre. J Clin Diagn Res. 2013; 7(7):1377-1382.

23. Su SY, Bell D, Hanna EY. Esthesioneuroblastoma, neuroendocrine carcinoma, and sinonasal undifferentiated carcinoma: differentiation in diagnosis and treatment. Int Arch Otorhinolaryngol. 2014; 18(Suppl 2):S149-S156.

24. Bell D, Hanna EY, Weber RS, et al. Neuroendocrine neoplasms of the sinonasal region. Head Neck. 2016;38 Suppl 1:E2259-E2266.

25. Menon S, Pai P, Sengar M, Aggarwal JP, Kane SV. Sinonasal malignancies with neuroendocrine differentiation: case series and review of literature. Indian J Pathol Microbiol. 2010;53(1):28-34.

26. Zhang M, Zhou L, Wang DH, Huang WT, Wang SY. Diagnosis and management of esthesioneuroblastoma. ORL J Otorhinolaryngol Relat Spec. 2010;72(2):113-118. 


\section{Publish your work in this journal}

OncoTargets and Therapy is an international, peer-reviewed, open access journal focusing on the pathological basis of all cancers, potential targets for therapy and treatment protocols employed to improve the management of cancer patients. The journal also focuses on the impact of management programs and new therapeutic agents and protocols on

patient perspectives such as quality of life, adherence and satisfaction. The manuscript management system is completely online and includes a very quick and fair peer-review system, which is all easy to use. Visit http://www.dovepress.com/testimonials.php to read real quotes from published authors.

Submit your manuscript here: http://www.dovepress.com/oncotargets-and-therapy-journal 